Lep. Rev. (1968) 39, 3, 143-146

\title{
Decompression of the Ulnar and Median Nerves in Leprous Neuritis ${ }^{\star}$
}

\author{
A. C. PARIKH \\ Medical Officer \\ R. GANAPATI \\ Research Officer \\ K. B. KOTHARE \\ Physiotherapist \\ Acuorth Leprosy Hospital, Wadala, Bombay 31 \\ S. C. DIVEKAR \\ Assistant Research Officer, V.R.A. Project on 'Nerve Lesions in Leprosy', \\ Tata Department of Plastic Surgery, J.J. Group of Hospitals, 3ombay
}

This study was undertaken to assess the value of partial decompression of the ulnar and median nerves in leprosy to relieve pain due to neuritis and to improve muscle function.

Muir (1948) was of the opinion that a painful swelling of nerves following progressive paralysis was suitable for decompression. 'Splitting of the nerve sheath will give relief and conserve function in the most severe cases.' Cochrane (1964) pointed out that the operation on all nerves should be replaced by a much more cautious approach; however, if a nerve abscess is suspected the nerve should be explored forthwith, for if, under these conditions, surgical interference is not initiated, gross damage may result-a damage far more crippling than that caused by any operative interference. Gramberg (1955) has reported that after decompression pain and paraesthesia disappear in nearly all cases.

\section{MATERIAL AND METHODS}

Thirteen leprosy patients (10 males and 3 females) of ages ranging from 16 to 57 years attending the out-patient clinic of the Acworth Leprosy Hospital, Wadala, Bombay, were selected for the study.
The duration of the disease as given by the patients ranged from 6 months to 16 years. The type of leprosy in these patients was as follows:-

TABLE 1

\begin{tabular}{lc}
\hline Type of Leprosy & No. of Patients \\
\hline Tuberculoid & 10 \\
Borderline & 1 \\
Lepromatous & 2 \\
\hline Total & 13 \\
\hline
\end{tabular}

All the patients were suffering from severe ulnar neuritis with or without involvement of median nerves, resulting in severe pain along the course of the nerves not responding to oral analgesics and perineural injections of hydrocortisone or intradermal 'Hydnocreol' along the course of the nerve or local ethyl chloride spray, etc.

Table 2 shows the types of disease and site of nerve lesions.

* Paper read at the Xth All India Conference of the Indian Association of Dermatologists and Venereologists held at Cuttack in January, 1968. 
TABLE 2

\begin{tabular}{lcccccc}
\hline & $\begin{array}{c}\text { No. of } \\
\text { Patients }\end{array}$ & $\begin{array}{c}\text { Rt. Ulnar } \\
\text { alone }\end{array}$ & $\begin{array}{c}\text { Rt. Median } \\
\text { and Ulnar }\end{array}$ & $\begin{array}{c}\text { Lt. Ulnar } \\
\text { alone }\end{array}$ & $\begin{array}{c}\text { Lt. Median } \\
\text { and Ulnar }\end{array}$ & Abscess \\
\hline Tuberculoid & 10 & 3 & 3 & Nil & $8^{*}$ \\
Borderline & 2 & Nil & Nil & Nil & Nil & Nil \\
Lepromatous & 13 & 2 & Nil & Nil \\
\hline Total & & 3 & & 8 \\
\hline
\end{tabular}

* One patient showed calcification inside the nerve sheath (Fig l) (detected during operation). Another patient had an abscess in the median cutaneous nerve of the forearm as well as ulnar.

Detailed clinical examination with special emphasis on the severity of the pain and paraesthesia was done. The gradation of the muscular weakness was assessed both clinically and with the help of the electric stimulator, before and after surgical operations as shown below:-

The muscle is stimulated at its motorpoint (neuromuscular junction) by the galvanic units and later by the faradic unit.

Findings. The normal muscle responses are brisk both to the galvanic and faradic units. T'he completely denervated muscle responds sluggishly to the galvanic unit but does not respond to faradic unit. The partially denervated muscle responds briskly to the galvanic unit and only with a very high output to the faradic unit. The difference between the galvanic and faradic units is noted and muscle weakness is graded accordingly.

The technique of nerve decompression:

Premedication used: Chlorpromazine hydrochloride (Largactil) $25 \mathrm{mgm}$. and pethidine $50 \mathrm{mg}$. injection I.M.

Anaesthesia: Brachial plexus block using 20 c.c. of $1 \%$ xylocaine with or without adrenaline (1: 1000 aqueous solution). A tourniquet is applied to the upper arm.

The ulnar nerve is exposed from the middle of the arm to the upper quarter of the forearm. The superficial and deep fascia and medial intermuscular septum are incised exposing the nerve in the arm. The nerve is followed distally up to the upper quarter of forearm by slitting the fibrous origin of the flexor carpi ulnaris over the ulnar groove. No attempt is made to mobilise the nerve or to incise the epineurium or to transpose the nerve anteriorly. A caseous nerve abscess in relation to the ulnar nerve generally took the form of a well encapsulated almondshaped swelling (Fig 2). No pedicle was seen, the swelling projecting out from the interior of the nerve. The contents were almost solid or semisolid and hence could not be 'drained' away in the conventional sense. Its roots were in the interior of the nerve from where the caseous material was picked or scooped off, taking care not to damage normal looking fibres. At times, however, the entire nerve was converted into a caseous cone with an epineural shell (Fig 3).

Median nerve: This nerve is exposed in the lower third of the forearm and followed into the hand by incising the flexor retinaculum and palmar aponeurosis. The maximal thickening and induration was generally seen and felt to be proximal to the wrist just distal to the sublimus belly.

The criteria of improvement were (1) relief from pain and (2) improvement in the muscle functions as judged clinically and by electrical assessment.

The period of follow-up after surgery ranged from 10 months to $2 \frac{1}{2}$ years (except in one patient where the follow-up period was only 3 months).

As a result of surgical decompression, pain of a moderate to severe extent was relieved in all patients except 3. Persistent excruciating pain, often experienced by patients in spite of oral and parenteral analgesic treatment or perineural and antiphlogistic therapy should therefore be taken as an indication for surgery. The relief obtained by nearly $77 \%$ of the patients would by itself justfy the surgical intervention. 


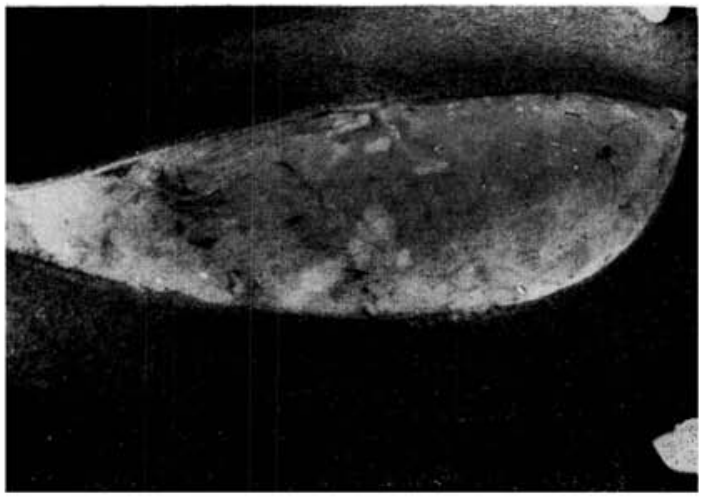

FIG. 1

Calcification inside the nerve sheath.

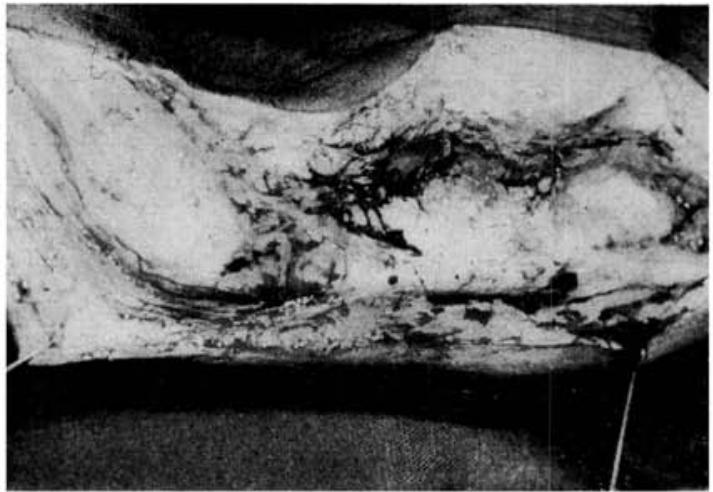

FIG. 2

Encapsulated almond-shaped swelling.

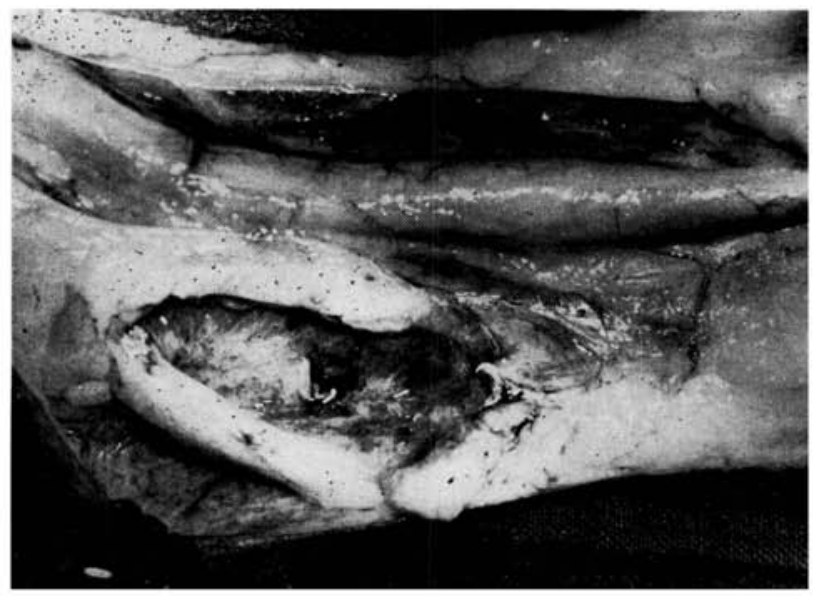

Fig. 3

Caseous cone with an epineural shell. 


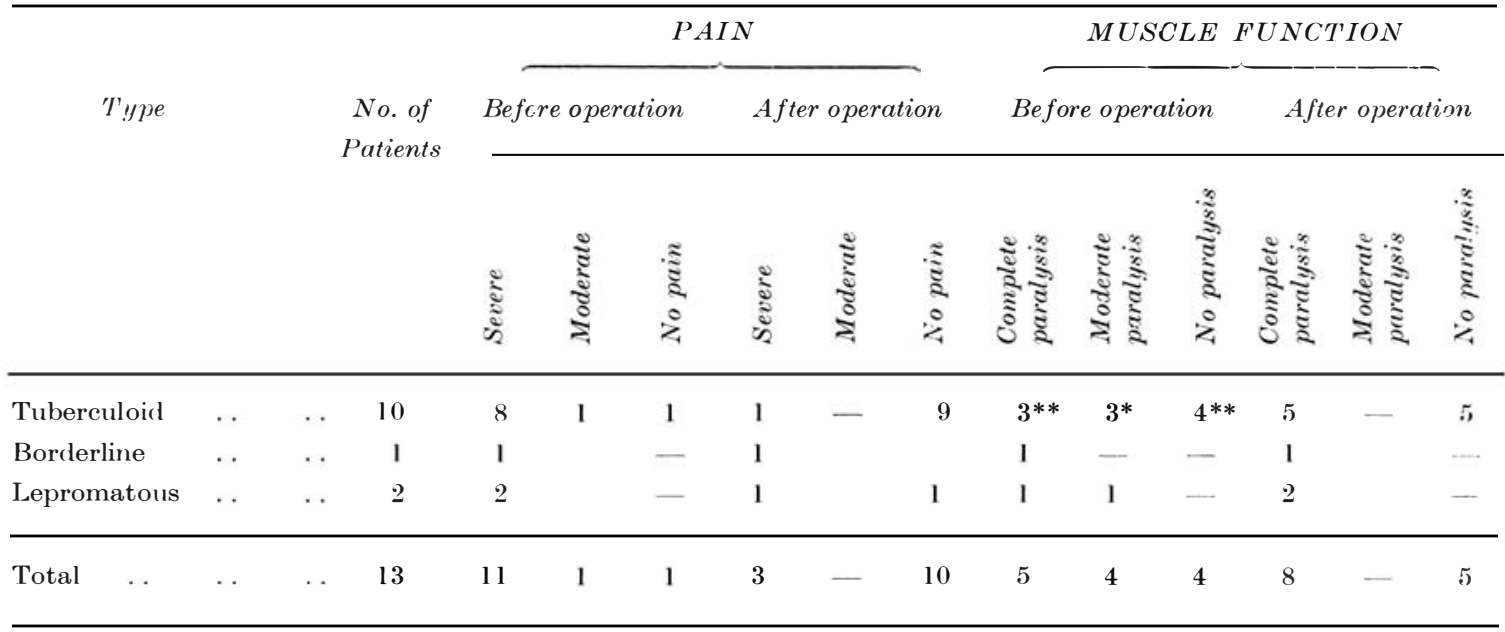

* Of the 3 patients who had moderate paralysis, one had an abscess.

** All these patients had an abscess of ulnar nerve.

Assessment of muscle function has shown that 4 patients who did not have any paralysis preoperatively were not adversely affected as a result of the operation. One patient who had moderate paralysis showed some improvement after surgery, while in 3 moderate patients the progressive paralysis was unchecked by decompression, since only the external pressure on the individual nerve was relieved and the nerve fibres themselves were not subjected to any interference during surgery. The progressive paralysis observed in these patients may be the result of degeneration of the nerve due to the disease process itself.

\section{SUMMARY}

Follow-up study of 13 surgically decompressed patients with severe leprous ulnar and median neuritis who did not respond to medical measures is presented. In all patients except 3, pain was completely relieved; improvement in muscle function was seen in only one patient and 4 patients who had visible caseation remained unchanged. Three patients with progressive nerve lesions became progressively worse after surgery.

\section{ACKNOWLEI.GEMENTS}

We are giateful to Dr. N. Figueredo, Special Officer, and Dr. N. D. Katdare, Superintendent, Acworth Leprosy Hospital, Wadala, Bombay 31, India, for invaluable guidance. The surgery was carried out at the Tata Department of Plastic Surgery, J.J. Group of Hospitals, Bombay, and we are grateful to Dr. N. H. Antia, Chief, Tata Depariment of Plastic Surgery, and Dr. D. K. Dastur, Neuro-pathologist, J.J. Group of Hospitals, for guiding this project.

\section{REFERENCES}

1. Annual Report (1966) of the Tata Department of Plastic Surgery. J.J. Group of Hospitals and Project on Rehabilitation in Leprosy and Burns and Nerve Lesions in Leprosy (V.R.A.). Department of Health, Education and Welfare, United States Government, 147-148.

2. COChRANE, R. G. and DAVEY T. F. (1964). Leprosy in Theory and Practice, Second Edition, Bristol, John Wright \& Sons Ltd., 414.

3. MUIR, E. (1948). Manual of Leprosy, Edinburgh: E \& S Livingstone Ltd., 137-138.

4. Gramberg, K. P. C. A. (1955).Int. J. Lepr., 23, $115-123$.

\section{Leprosy Review}

